\title{
Pengaruh Reward, Punishment dan Motivasi Terhadap Produktivitas Kerja Karyawan pada CV Derowak Jaya di Kabupaten Serang-Banten
}

\author{
Suhartini ${ }^{1}$ \\ Universitas Serang Raya \\ suhartini@unpas.ac.id
}

\begin{abstract}
Abstrak
Tujuan dari penelitian ini untuk mengetahui pengaruh Reward, Punishment dan Motivasi terhadap Produktivitas Kerja Karyawan pada CV Derowak Jaya di Kabupaten Serang-Banten. Populasi juga sebagai Responden sebanyak 40 orang merupakan karyawan yang bekerja di CV Derowak Jaya di Kabupaten Serang-Banten, adalah sampel jenuh. Pengumpulan data melalui penyebaran kuesioner ditambah sumber data lainnya sesuai dengan kebutuhan penelitian yakni data primer dan data skunder dan sumber lainnya.

Uji yang digunakan uji validitas, reliabilitas asumsi klasik serta analisis yang digunakan adalah regresi ganda. Hasil analisis secara parsial melalui uji t mendapatkan Reward (X1) memiliki pengaruh yang signifikan terhadap variabel Produktifitas (Y), dan Punishmen (X2) memiliki pengaruh yang signifikan terhadap variabel Produktivitas (Y), sedangkan variabel Motivasi (X3) tidak berpengruh secara signifikan terhadap Produktivitas. Secara simultan melalui uji F variabel Reward, Punihsmen dan Motivasi Uji f diadapatkan mempunyai pengruh yang positif dan signifikan, diketahui nilai $\mathrm{f}$ hitung adalah 42,709 hal ini menunjukan variabel independen secara bersama-sama berpengaruh terhadap variabel dependen, analisis koefisien determinasi diperoleh nilai sebesar 78,1 \% yang artinya bahwa besarnya hubungan variabel independen terhadap variabel dependen sebesar $78,1 \%$ sisanya sebesar $21,9 \%$ diterangkan oleh variabel lainnya yang tidak diteliti oleh penulisan.
\end{abstract}

Kata Kunci: Reward, Punishment, Motivasi dan Produktivitas Kerja

\begin{abstract}
The purpose of this study was to determine the effect of Reward, Punishment and Motivation on Employee Productivity at CV Derowak Jaya in Serang-Banten Regency. The population as well as 40 respondents as employees who work at CV Derowak Jaya in Serang-Banten Regency, is a saturated sample. Data collection through questionnaires plus other data sources in accordance with research needs, namely primary data and secondary data and other sources.

The test used validity test, classical assumption reliability and the analysis used was multiple regression. The results of partial analysis through the t-test get Reward (X1) have a significant effect on Productivity (Y), and Punishmen (X2) variables have a significant influence on Productivity variables $(Y)$, while the Motivation variable (X3) does not significantly influence Productivity. Simultaneously through the F test Reward variable, Punihsmen and Motivation Test fobtained has a positive and significant effect, it is known that the value off arithmetic is 42.709 this shows the independent variables jointly influence the dependent variable, the analysis of the coefficient of determination obtained a value of $78.1 \%$, which means that the magnitude of the
\end{abstract}

${ }^{1}$ Korespondensi: Suhartini. Universitas Serang Raya. Jl. KH. Amin Jasuta No 15C Kaloran Brimob, Serang. suhartini@ unpas.ac.id 
relationship of the independent variable to the dependent variable is $78.1 \%$, the remaining $21.9 \%$ is explained by other variables not examined by writing.

\section{Keywords: Reward, Punishment, Motivation and Work Productivity}

\section{Pendahuluan}

Perkembangan dunia usaha dari waktu ke waktu menunjukkan persaingan yang luar biasa di akhir dekade ini. Era globalisasi yang didiikuti teknologi dan informasi merambah bukan saja pada perusahaan besar tetapi juga pada perusahaan kecil bahkan pada usaha perorangan. Upaya pembenahan dari berbagai sisi pada perusahaan terus menerus dilakukan agar perusahaan dapat bertahan dan bahkan berkembang sehingga tujuan perusahaan dapat tercapai dengan tepat dan baik. Perkembangan yang signifikan tidak mungkin dapat tercapai apabila karyawan sebagai kunci penggerak roda organisasi tidak pruduktif. Produktivitas Kerja Karyawan yang tinggi dalam sebuah organisasi di bidang barang atau jasa, merupakan harapan bagi semua pihak. Maka jelaslah sumber daya manusia asset yang hartus diperhatikan dan tidak bisa diabaikan. Berkaitan dengan produktifitas kerja karyawan salah satu indicator yang harus dipenuhi adalah bagaimana perusahaan dapat memberikan reward dan punishment secara adil sehingga karyawan termotivasi untuk melakukan aktivitas kerja dengan sungguh-sungguh, merasakan kepuasan dan nyaman dalam bekerja.

Pemberian reward merupakan salah satu pelaksanaan fungsi sumber daya manusia sebagai bentuk perhatian positif daru perusahaan penyemangat, partisipasi, yang mempunyai tujuan untuk memotivasi, memberi semangat, mendorong partisipasi sehingga karywan mampu memberikan hasil terbaik untuk perusahan.. Demikian besarnya peran reward bagi karyawan karena besarnya reward terkadang merupakan pencerminan prudoktivitas kerja yang diberikan oleh karyawan kepada perusahaan yang dilandasi tanggungjawab, rasa memiliki yang tinggi kepada perusahaan, dan sebaliknya perusahaan mengapresiasi hasil kerja karyawan dengan baik dan membalasnya dalam bentuk pengharagaan yang bermanfaat dan dapat dirasakan langsung oleh karaywan. Diharapkan Pemberian reward yang baik kepada karyawan dapat menurunkan tindakan-tindakan yang mengarah pada terhambatnya tujuan organisasi, oleh karena itu pemberian reward harus dikelola baik karena akan membantu perusahaan dalam mencapai tujuannya. Sebaliknya tanpa reward yang cukup, produktivitas kerja menurun, tidak jarang karyawan melakukan indisipliner, melakukan mogok kerja, melakukan tindakan-tindakan fisik, dan pada akhirnya karyawan tersebut akan meninggalkan perusahaan.

Disisi lain, Perusahaan perlu memberikan Punishment bagi karyawan sebagai bentuk pembinaan, disiplin, pembinaan, pengawasan, agar karyawan disiplin dan mematuhi aturan yang ditetapkan oleh perusahaan. Punishmen tiada lain merupakan ancaman, hukuman yang bertujuan untuk memperbaiki kinerja karyawan sehingga karyawan dapat menghindari pelanggranpelanggaran yang tidak diinginkan bersama. Begitu pentingnya punishmen sehingga merupakan indicator yang tidak boleh luput dalam kegiatan pengelolaan sumber daya manusia. Pelaksanaan punishment yang tidak pada tempatnya akan menimbulkan produktivitas kerja karyawan menurun. Namun sebaliknya pelaksanaan punismen yang adil dan terkendali akan meningkatkan produktivitas karyawan dalam bekerja.

CV. Derowak Jaya ini merupakan sebuah perusahaan bisnis yang bergerak dibidang kontruksi, perdagangan, pengadaan barang dan jasa, perusahaan ini memiliki peran penting dalam meningkatkan mutu serta kualitas baik dari sumber daya manusia maupun dari output yang dihasilkan. Fenomena yang terjadi pada 2 (dua) tahun terkahir menujukkan produktifitas yang fluktuatif dan tidak stabil bahkan kecenderungan menurun. Dalam pra peneltian yang dilakukan ternyata terdapat ketidakpuasan karyawan terhadap perlakuan reward dan punishmen sehingga karyawan tidak termotivasi dan bekerja tidak maksimal seperti yang diharapkan. Dari 40 
responden menyatakan bahwa $60 \%$ karyawan mengalami penurunan motivasi yang berdampak pada produktivitas kerja karyawan akibat lemahnya penerapan reward dan punishment terhadap karyawan. Sebesar 70\% mengatakan bahwa perusahaan terkesan diskriminatif dalam memberi hukuman bagi karyawan yang melakukan kesalahan, dan 60\% karyawan mengatakan ketidakkonsistenan perusahaan memberi penghargaan dan hukuman membuat motivasi kerja mereka menurun dan otomatis membuat produktivitas kerja pun menjadi turun.

Tujuan penelitian ini untuk mengetahui secara parsial pengaruh reward terhadap produktivitas kerja karyawan, untuk mengetahui secara parsial pengaruh punishment terhadap produktivitas kerja karyawan, untuk mengetahui secara simultan pengaruh reward, punishment dan motivasi terhadap produktivitas kerja karyawan.

\section{Metode Penelitian}

Jenis penelitian yang digunakan dalam penelitian ini adalah penelitian kuantitatif. Lokasi dalam penelitian ini adalah CV Derowak Jaya di Kabupaten Serang-Banten. Variabel yang diteliti adalah Reward, Punishment, Motivasi dan Produktivitas Kerja. Adapun yang menjadi populasi dalam penelitian ini adalah karyawan yang bekerja pada perusahaan CV Derowak Jaya di Kabupaten Serang-Banten yang berjumlah 40 karyawan.Teknik yang digunakan adalah Sampling Jenuh, yang artinya adalah teknik penentuan sampel bila semua anggota populasi digunakan sebagai sampel, yaitu berjumlah 40 karyawan yang dijadikan sampel.

\section{Validitas dan Reliabilitas}

Dalam uji validitas ini penulis menyebarkan kuesioner kepada 40 responden yang berisikan 8 item pernyataan untuk variabel Reward, 10 item pernyataan untuk variabel Punishment, 8 item untuk variabel Motivasi dan 9 item untuk variabel Produktivitas Kerja. Uji validitas dilakukan pada setiap item pernyataan, dengan tingkat kesalahan $5 \%$ jika $r$ _hitung $>r$ _tabel maka item pernyataan tersebut dinyatakan valid.

Reliabilitas instrument menunjukkan pengertian bahwa suatu instrument cukup dapat dipercaya untuk digunakan sebagai alat pengumpul data karena instrument tersebut sudah baik.

\section{Uji Normalitas}

Uji normalitas bertujuan untuk menguji apakah residual data dari model regresi memiliki distribusi normal atau tidak. Uji Normalitas menggunakan program SPSS v.23, Uji Normalitas dalam penelitian ini menggunakan metode Kolmogrov-Smirnovjika hasil angka signifikansi (Sig) lebih kecil dari 0,05 maka data tidak terdistribusi normal.

\section{Analisis Regresi Linier Berganda}

Analisis Regresi Linier Berganda adalah suatu alat analisis peramalan nilai pengaruh dua variabel bebas atau lebih terhadap variabel terikat untuk membuktikan ada atau tidaknya hubungan fungsi antara dua variabel bebas atau lebih dengan satu variabel terikat untuk memprediksi atau meramalkan variabel - variabel lain.Perhitungan analisis regresi menggunakan program SPSS 23 dan adapun model kelayakan regresi linear di dasarkan pada hal-hal sebagai berikut:

1. Predictor yang digunakan sebagai variabel bebas harus layak, kelayakan ini diketahui jika angka standar Error Of Estimate $<$ Standar Deviation.

2. Data harus berdistribusi normal.

Untuk melihat pengaruh Reward $\left(\mathrm{X}_{1}\right)$, Punishment $\left(\mathrm{X}_{2}\right)$, Motivasi $\left(\mathrm{X}_{3}\right)$ dan Produktivitas Kerja (Y), maka digunakan analisis regresi dengan persamaan sebagai berikut : 


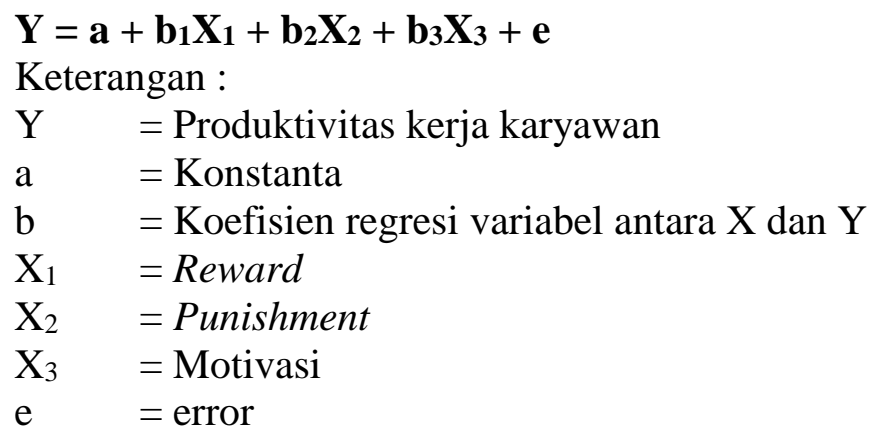

\section{Uji Parsial (Uji-t)}

Pengujian ini bertujuan untuk menguji model regresi variabelindependen (Reward, Punishment dan Motivasi) secara parsial berpengaruh signifikan atau tidak terhadap variabel dependen (Produktivitas Kerja Karyawan) dengan tingkat signifikasi a $=5 \%$ secara parsial. Berikut hasil pengujian hipotesis Uji t.

\section{Uji F}

Uji $F$ digunakan untuk mengetahui tingkat signifikansi pengaruh variabel-variabel independen secara bersama-sama (Simultan) terhadap variabel dependen, dasar pengambilan keputusan sebagai berikut :

1. $\mathrm{Ho}=0$ berarti tidak ada pengaruh yang signifikan antar Reward $\left(\mathrm{X}_{1}\right)$, Punishment $\left(\mathrm{X}_{2}\right)$ dan Motivasi $\left(\mathrm{X}_{3}\right)$ terhadap Produktivitas Kerja Karyawan (Y).

2. Ho $>0$ berarti ada pengaruh yang signifikan antar Reward $\left(\mathrm{X}_{1}\right)$, Punishment $\left(\mathrm{X}_{2}\right)$ dan Motivasi $\left(\mathrm{X}_{3}\right)$ terhadap Produktivitas Kerja Karyawan $(\mathrm{Y})$.

3. Pengujian pengaruh variabel bebas secara simultan bersama-sama terhadap variabel terikatnya dilakukan dengan mengunakan Uji $\mathrm{F}$ dengan melihat $\mathrm{F}$ tabel dan Nilai Signifikasinya.

Untuk memperoleh $\mathrm{F}_{\text {tabel }}$ dapat dilakukan dengan rumus :
a. df1 $=\mathrm{K}-1$
b. df1 $=4-1=3$
c. $\mathrm{df} 2=\mathrm{n}-\mathrm{k}-1$
d. df $2=40-3-1=36$
e. dari df $1=3$ dan $\mathrm{df} 2=36$ maka dapat diketahui $\mathrm{F}_{\text {tabelsebesar } 2,87}$ 


\section{Hasil}

\section{Uji Normalitas}

Tabel 1. Hasil Kolmogorov-Smirnov

One-Sample Kolmogorov-Smirnov Test

\begin{tabular}{|ll|r|}
\hline & & \multicolumn{1}{|c|}{$\begin{array}{c}\text { Unstanda } \\
\text { rdized } \\
\text { Residual }\end{array}$} \\
\hline $\mathrm{N}$ & Mean & 40 \\
Normal Parameters ${ }^{\mathrm{a}, \mathrm{b}}$ & Std. & 1,522000000 \\
& Deviation & 66 \\
Most Extreme & Absolute &, 115 \\
Differences & Positive &, 073 \\
Test Statistic & Negative & -115 \\
Asymp. Sig. (2-tailed) & &, 115 \\
& &, $195^{\mathrm{c}}$ \\
\hline
\end{tabular}
a. Test distribution is Normal.
b. Calculated from data.
c. Lilliefors Significance Correction.

Berdasarkan tabel Kolmogrov-Smirnov diatas menunjukan bahwa signifikan sebesar 0,195 taraf signifikan yaitu > 0.05 maka dapat disimpulkan bahwa Uji Normalitas terpenuhi atau data berdistribusi normal.

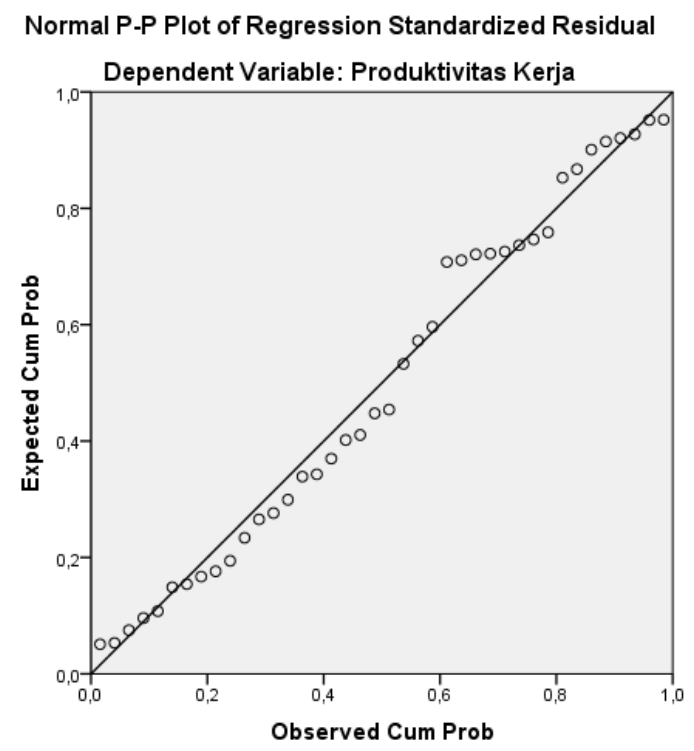

Sumber : Hasil Pengolahan Data SPSS V.23

Gambar 1. Uji Normalitas Grafik P-P Plot

Selain uji One-Sample Kolmogrov-Smirnov, penulis juga menguji P-P Plot Of Regression. Dari grafik diatas dapat disimpulkan bahwa model regresi memenuhi asumsi normalitas, hal ini terlihat bahwa kurva pada grafik terlihat mengikuti dan mendekati diagonal. 


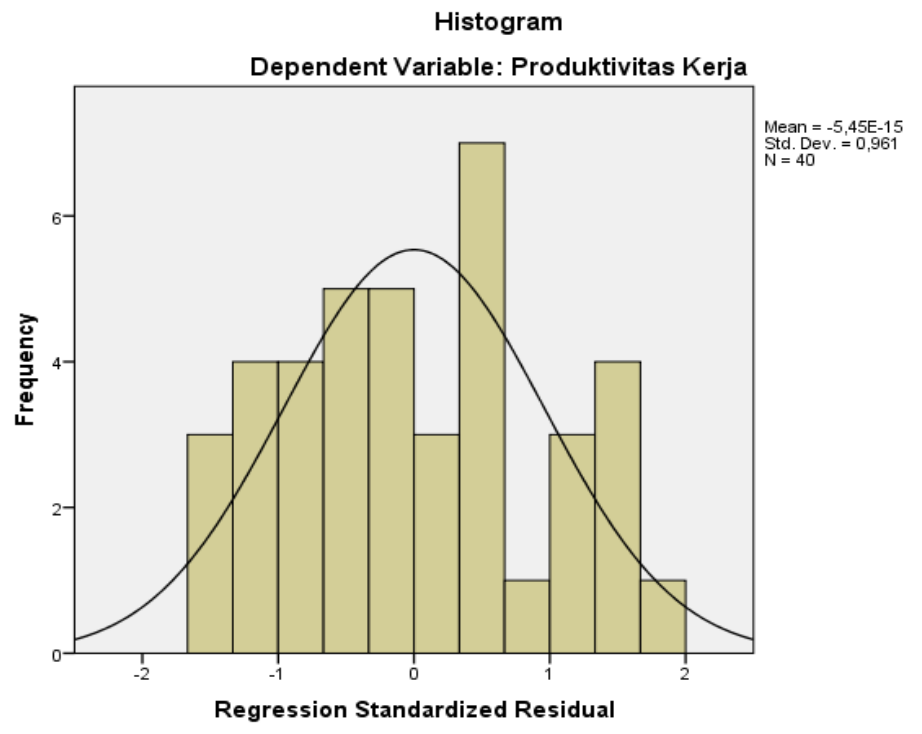

Sumber : Hasil Pengolahan Data SPSS V.23

Gambar 2. Uji Normalitas Histogram

Dengan melihat tampilan grafikhistogram diatas dapat disimpulkan bahwa model regresi memenuhi asumsi normalitas, hal ini dilihat bahwa kurva pada grafik histogram membentuk pola lonceng.

\section{Analisis Regresi Linier Berganda}

Tabel 3. Analisis Regresi Linier Berganda

Coefficients $^{\mathrm{a}}$

\begin{tabular}{|c|c|c|c|c|c|c|}
\hline \multirow[b]{2}{*}{ Model } & & \multicolumn{2}{|c|}{$\begin{array}{l}\text { Unstandardized } \\
\text { Coefficients }\end{array}$} & \multirow{2}{*}{$\begin{array}{r}\begin{array}{r}\text { Standardiz } \\
\text { ed Coefficients }\end{array} \\
\text { Beta }\end{array}$} & \multirow[b]{2}{*}{$\mathrm{T}$} & \multirow[b]{2}{*}{ Sig. } \\
\hline & & $\mathrm{B}$ & Std. Error & & & \\
\hline \multirow{4}{*}{ t) } & (Constan & 2,115 & 3,867 & &, 547 & ,588 \\
\hline & Reward & ,656 & ,094 & ,662 & 6,997 &, 000 \\
\hline & Punishm & ,432 & ,128 & ,322 & 3,384 & ,002 \\
\hline & Motivasi &,- 027 &, 075 &,- 028 &,- 353 & ,726 \\
\hline
\end{tabular}

a. Dependent Variable: Produktivitas Kerja

Berdasarkan hasil perhitungan pada tabel diatas, diperoleh bentuk persamaan regresi berganda sebagai berikut :

$$
\mathrm{Y}=2,115+0,656 \mathrm{X}_{1}+0,432 \mathrm{X}_{2}+-0,027 \mathrm{X}_{3}+\mathrm{e}
$$

Nilai koefisien regresi pada variabel bebasnya menggambarkan apabila diperkirakan variabel bebasnya naik sebesar satu unit dan nilai variabel bebas lainya diperkirakan konstanta atau sama dengan nol, maka variabel terikat diperkirakan bisa naik atau bisa turun sesuai dengan tanda koefisien regresi variabel bebasnya.

Dari persamaan regresi linier berganda diatas diperoleh nilai konstanta sebesar 2,115 artinya, jika nilai dari Reward, Punishment dan Motivasi sama dengan 0, maka tingkat atau besarnya Produktivitas Kerja adalah 2,115.

1. Tanda koefisien regresi untuk variabel bebas $X_{1}$ sebesar 0,656 menunjukan koefisien regresi Rewardterhadap Produktivitas Kerja Karyawan. Karena nilainya positif maka setiap kenaikan Rewardsebesar 1\% maka Produktivitas Kerja Karyawan akan mengalami kenaikan sebesar 
65,6 persen. Begitupun sebaliknya setiap penurunan Rewardsebesar $1 \%$ akan menaikan Produktivitas Kerja Karyawan sebesar $-65,6$ persen.

2. Tanda koefisien regresi untuk variabel bebas $X_{2}$ sebesar 0,432 menunjukan koefisien regresi Punishment terhadap Produktivitas Kerja Karyawan. Karena nilainya positif maka setiap kenaikan Punishment sebesar 1\% maka Produktivitas Kerja Karyawan akan mengalami kenaikan sebesar 43,2 persen. Begitupun sebaliknya setiap penurunan Punishmentsebesar 1\% akan menaikan Produktivitas Kerja Karyawan sebesar -43,2 persen.

3. Tanda koefisien regresi untuk variabel bebas $\mathrm{X}_{3}$ sebesar $-0,027$ menunjukan koefisien regresi Motivasiterhadap Produktivitas Kerja Karyawan. Karena nilainya negatif maka setiap penurunanMotivasisebesar 1\% maka Produktivitas Kerja Karyawan akan mengalami kenaikan sebesar -2,7 persen. Begitupun sebaliknya setiap kenaikanMotivasisebesar 1\% akan menaikan Produktivitas Kerja Karyawan sebesar 2,7 persen.

\section{Uji t}

Tabel 4. Hasil Uji Parsial (Uji-t)

Coefficients $^{\mathrm{a}}$

\begin{tabular}{|c|c|c|c|c|c|c|}
\hline \multirow[b]{2}{*}{ Model } & & \multicolumn{2}{|c|}{$\begin{array}{l}\text { Unstandardized } \\
\text { Coefficients }\end{array}$} & \multirow{2}{*}{$\begin{array}{r}\begin{array}{r}\text { Standardiz } \\
\text { ed Coefficients }\end{array} \\
\text { Beta }\end{array}$} & \multirow[b]{2}{*}{$\mathrm{T}$} & \multirow[b]{2}{*}{ Sig. } \\
\hline & & $B$ & Std. Error & & & \\
\hline $1 \mathrm{t})$ & (Constan & 2,115 & 3,867 & &, 547 & ,588 \\
\hline & Reward & ,656 & ,094 & ,662 & 6,997 &, 000 \\
\hline ent & & ,432 & ,128 & ,322 & 3,384 & ,002 \\
\hline & Motivasi &,- 027 & ,075 &,- 028 &,- 353 & ,726 \\
\hline
\end{tabular}

a. Dependent Variable: Produktivitas Kerja

Berdasarkan hasil output diatas, dapat dijelaskan hasil pengujian hipotesis secara masingmasing sebagai berikut :

1. Secara parsial, pengaruh Reward pada kolom t menunjukan nilai thitung sebesar 6,997. Hal ini berarti lebih besar jika dibandingkan dengan nilai $t$ tabel yaitu sebesar 2,026 yang diperoleh dari $(n-3=40-3=37$ ) dengan taraf signifikansi $\alpha=5 \%$. Kemudian nilai sig diperoleh sebesar 0,000 yang berarti lebih kecil dari taraf signifikasi $\alpha=0,05$. Maka dari itu disimpulkan bahwa $\mathrm{t}$ hitung $>\mathrm{t}$ tabel $(6,997>2,026)$. Dan tingkat signifikasi $0,000<0,05$, sehingga diambil keputusan Ho ditolak dan Ha diterima, Hal ini berarti variabel independen (Reward) secara individual berpengaruh positif dan signifikan terhadap variabeldependen (Produktivitas Kerja Karyawan).

2. Secara parsial, pengaruh Punishment pada kolom t menunjukan nilai thitung sebesar 3,384 hal ini berarti lebih besar jika dibandingkan dengan nilai $t$ tabel yaitu sebesar 2,026 yang diperoleh dari $(n-3=40-3=37$ ) dengan taraf signifikasi $\alpha=5 \%$. Kemudian nilai sig diperoleh sebesar 0,002 yang berarti lebih kecil dari taraf signifikasi $\alpha=0,05$. Maka dari itu dismpulkan bahwa $t_{\text {hitung }}>t_{\text {tabel }}(3,384>2,026)$. Dan tingkat signifikasi $0,002<0,05$, sehingga diambil keputusan Ho ditolak dan Ha diterima, Hal ini berarti variabelindependen (Punishment) secara individual berpengaruh positif dan signifikan terhadap variabel dependen (Produktivitas Kerja Karyawan).

3. Secara parsial, pengaruh Motivasi pada kolom t menunjukan nilai thitung sebesar $-0,353$ hal ini berarti lebih kecil jika dibandingkan dengan nilai $t$ tabel yaitu sebesar 2,026 yang diperoleh dari $(n-3=40-3=37)$ dengan taraf signifikasi $\alpha=5 \%$. Kemudian nilai sig diperoleh sebesar 
0,726 yang berarti lebih besar dari taraf signifikasi $\alpha=0,05$. Maka dari itu disimpulkan bahwa $t_{\text {hitung }}<\mathrm{t}_{\text {tabel }}(-0,353<2,026)$. Dan tingkat signifikasi $0,687>0,05$, sehingga diambil keputusan Ho diterima dan Ha ditolak, Hal ini berarti variabelindependen (Motivasi) secara individual tidak berpengaruh positif dan signifikan terhadap variabel dependen (Produktivitas Kerja Karyawan).

\section{Uji F}

Tabel 5. Uji Simultan (Uji-F)

ANOVA $^{\mathrm{a}}$

\begin{tabular}{|c|c|c|c|c|c|}
\hline Model & $\begin{array}{l}\text { Sum of } \\
\text { Squares }\end{array}$ & Df & $\begin{array}{l}\text { Mean } \\
\text { Square }\end{array}$ & $\mathrm{F}$ & Sig. \\
\hline 1 sion ${ }^{\text {Regres }}$ & 321,552 & 3 & 107,184 & $\begin{array}{r}42,7 \\
09\end{array}$ &, 000 \\
\hline al Residu & 90,348 & 36 & 2,510 & & \\
\hline Total & 411,900 & 39 & & & \\
\hline
\end{tabular}

a. Dependent Variable: Produktivitas Kerja

b. Predictors: (Constant), Motivasi, Reward, Punishment

Berdasarkan tabel hasil perhitungan statistik uji f diatas menunjukan nilai $\mathrm{f}_{\text {hitung }}>\mathrm{f}$ tabel yaitu 42,709 > 2,87 maka dapat disimpulkan bahwa Ho ditolak Ha diterima. Berarti secara bersamasama (simultan)Reward $\left(\mathrm{X}_{1}\right)$, Punishment $\left(\mathrm{X}_{2}\right)$ dan Motivasi $\left(\mathrm{X}_{3}\right)$ berpengaruh positif dan signifikan terhadap variabel dependen (Produktivitas Kerja Karyawan).

Berdasarkan hasil SPSS v.23 diperoleh nilai $F$ hitung 42,709 dengan signifikasi $\mathrm{F}$ sebesar 0,000 dengan menggunakan tingkat signifikasi $5 \%$ maka nilai $\mathrm{F}$ tabel dengan df1 $=3$ dan df $2=$ $\mathrm{n}-\mathrm{k}-1=40-3-1=36$ diperoleh $\mathrm{f}$ tabel sebesar 2,87. Maka f hitung 42,709 $\mathrm{F}$ tabel 2,87 atau signifikasi $\mathrm{F}$ sebesar 0,000 dengan demikian Ho ditolak Ha diterima, sehingga hipotesis yang menyatakan terdapat pengaruh yang positif dan signifikan antara variabel Reward (X1), Punishment (X2) dan Motivasi (X3) secara bersama-sama (simultan) terhadap variabel Produktivitas Kerja Karyawan (Y) dapat diterima.

Persamaan regresinya adalah $\mathrm{Y}=2,115+0,656 \mathrm{X} 1+0,432 \mathrm{X} 2+-0,027 \mathrm{X} 3$. Hal ini dapat diartikan bahwa Produktivitas Kerja Karyawan tanpa didukung Reward (konstanta), Punishment (konstanta) dan Motivasi (konstanta) besarnya 2,115 dari setiap perubahan atau peningkatan bersama-sama antar variabel Reward, variabel Punishment, dan variabel Motivasi menentukan tingkat Produktivitas Kerja Karyawan. Setiap ada kenaikan satu point pada variabel Reward berakibat naiknya skor variabel Produktivitas Kerja Karyawan sebesar 0,656 , setiap ada kenaikan variabel Punishment berakibat naiknya skor Produktivitas Kerja karyawan sebesar 0,432 dan setiap ada penurunan variabel Motivasi berakibat naiknya skor Produktivitas Kerja Karyawan sebesar -0,027. Dengan demikian semakin tinggi Reward maka semakin tinggi pula Produktivitas Kerja Karyawan, semakin tinggi Punishment maka semakin tinggi pula Produktivitas Kerja Karyawan, dan semakin rendah Motivasi maka semakin rendah pula Produktivitas Kerja Karyawan baik secara sendiri maupun bersama-sama (simultan).

Dari perhitungan koefisien korelasi besarnya hubungan Reward (X1), Punishment (X2) dan Motivasi (X3) berpengaruh terhadap Produktivitas Kerja Karyawan (Y) sebesar 78,1\%. Sedangkan sisanya sebesar $21,9 \%$ diterangkan oleh variabel lainnya yang tidak diteliti oleh penulisan. 


\section{Kesimpulan}

Berdasarkan hasil analisis dan pembahasan yang telah dijelaskan diatas maka dapat ditarik kesimpulan sebagai berikut :

1. Berdasarkan hasil penelitian bahwa Reward berpengaruh positif dan signifikan terhadap Produktivitas Kerja. Di dapat hasil nilai $t$ hitung sebesar 6,997 hal ini berarti lebih besar jika dibandingkan dengan nilai $t$ tabel yaitu sebesar 2,026 yang diperoleh dari $(n-3=40-3=37$ ) dengan taraf signifikansi $\alpha=5 \%$. Kemudian nilai sig diperoleh sebesar 0,000 yang berarti lebih kecil dari taraf signifikasi $\alpha=0,05$. Maka dari itu disimpulkan bahwa $\mathrm{t}$ hitung $>\mathrm{t}$ tabel $(6,997>2,026)$. Dan tingkat signifikasi $0,000<0,05$, sehingga diambil keputusan Ho ditolak dan Ha diterima, Hal ini berarti variabel independen (Reward) secara individual berpengaruh positif dan signifikan terhadap variabeldependen (Produktivitas Kerja Karyawan).

2. Berdasarkan hasil penelitian bahwa Punishment berpengaruh positif dan signifikan terhadap Produktivitas Kerja. menunjukan nilai thitung sebesar 3,384 hal ini berarti lebih besar jika dibandingkan dengan nilai $t$ tabel yaitu sebesar 2,026 yang diperoleh dari $(n-3=40-3=37$ ) dengan taraf signifikasi $\alpha=5 \%$. Kemudian nilai sig diperoleh sebesar 0,002 yang berarti lebih kecil dari taraf signifikasi $\alpha=0,05$. Maka dari itu dismpulkan bahwa $t_{\text {hitung }}>t_{\text {tabel }}(3,384>$ 2,026). Dan tingkat signifikasi 0,002 <0,05, sehingga diambil keputusan Ho ditolak dan Ha diterima, Hal ini berarti variabelindependen (Punishment) secara individual berpengaruh positif dan signifikan terhadap variabel dependen (Produktivitas Kerja Karyawan).

3. Berdasarkan hasil penelitian bahwa Motivasi tidak berpengaruh positif dan signifikan terhadap Produktivitas Kerja. menunjukan nilai thitung sebesar -0,353 hal ini berarti lebih kecil jika dibandingkan dengan nilai $t$ tabel yaitu sebesar 2,026 yang diperoleh dari $(n-3=40-3=$ 37 ) dengan taraf signifikasi $\alpha=5 \%$. Kemudian nilai sig diperoleh sebesar 0,726 yang berarti lebih besar dari taraf signifikasi $\alpha=0,05$. Maka dari itu disimpulkan bahwa $t_{\text {hitung }}<\mathrm{t}_{\text {tabel }}(-$ $0,353<2,026)$. Dan tingkat signifikasi $0,687>0,05$, sehingga diambil keputusan Ho diterima dan Ha ditolak, Hal ini berarti variabelindependen (Motivasi) secara individual tidak berpengaruh positif dan signifikan terhadap variabel dependen (Produktivitas Kerja Karyawan).

4. Berdasarkan hasil penelitian bahwa Reward, Punishment dan Motivasi berpengaruh positif dan signifikan terhadap Produktivitas Kerja. menunjukan nilai $\mathrm{f}_{\text {hitung }}>\mathrm{f}_{\text {tabel }}$ yaitu 42,709 > 2,87 maka dapat disimpulkan bahwa Ho ditolak Ha diterima. Berarti secara bersama-sama ( simultan)Reward $\left(\mathrm{X}_{1}\right)$, Punishment $\left(\mathrm{X}_{2}\right)$ dan Motivasi $\left(\mathrm{X}_{3}\right)$ berpengaruh positif dan signifikan terhadap variabel dependen (Produktivitas Kerja Karyawan).

\section{Daftar Pustaka}

Hadari, Nawawi. 2011, “Manajemen Sumber Daya Manusia”. Gajah Mada University Press, Jakarta.

Sedamaryanti. 2011, "Sumber Daya Manusia”. Mandar Maju, Bandung.

Sugiono. (2014). Metode Penelitian Kuantitatif, Kualitatif, Dan R\&D. Cetakan Ke-21. Bandung: CV. Alfabeta.

Sutrisno. (2016). Manajemen Sumber Daya Manusia. Edisi Pertama. Jakarta: Kencana.

Yuniarsih dan Siswanto. 2011, "Manajemen Sumber Daya Manusia, Teori Aplikasi dan Isu Penelitian, Cetakan ketiga, CV. Alfabeta, Bandung.

Febrianti, Musadieq, Prasetya. (2014). "Pengaruh Reward Dan Punishment Terhadap Motivasi Kerja Serta Dampaknya Terhadap Kinerja (Studi pada Karyawan PT. Panin Bank Tbk. Area Mikro Jombang)”. Jurnal Administrasi Bisnis. Vol. 12 No. 1.

Hakim, A. Khairul. (2011). "Pengaruh Kompensasi Dan Motivasi Terhadap

Produktivitas Kerja Pegawai”.Jurnal Manajemen \& Bisnis. Vol 11 No. 02 ISSN-16937619. 
Hindriari, Reni. (2018). "Pengaruh Motivasi Terhadap Produktivitas Kerja Karyawan Pada Pt Usaha Teknik Indonesia”. Jurnal Madani. Ilmu Pengetahuan, Teknologi, Dan Humaniora. Vol. 1, No. 1 (235-352), ISSN : 2615-1995, E-ISSN : 2615-0654.

Koencoro, Musadieq, dan Susilo. (2013). "Pengaruh RewardDan Punishment Terhadap Kinerja (Survei Pada Karyawan PT. INKA (Persero) Madiun)”. Jurnal Administrasi Bisnis. Vol. 5. No. (2).

Rumondor, Vico Wentri. (2013). "Motivasi, Disiplin Kerja, Dan Kepemimpinan Terhadap Produktivitas Kerja Pada Badan Kepegawaian Dan Diklat Daerah Minahasa Selatan”. Jurnal Emba. Vol.1 No.4 Hal. 1042-1052, ISSN-2303-1174.

Saputra, Nurlina, Hasan. (2017). "Pengaruh Reward (Penghargaan) Dan Punishment (Sanksi) Terhadap Produktivitas Kerja Karyawan Pt. Kereta Api Indonesia (Persero) Divisi Regional Ii Sumatera Barat". Jurnal Manajemen dan Kewirausahaan. Volume 8, Nomor 1, ISSN:2086-5031.

Solikah, Setyowati, Sanosra. (2016). "Pengaruh Reward, Punishment Dan Motivasi Kerja Terhadap Produktivitas Kerja Karyawan Pada Ptpn Xii (Persero) Kebun Jatirono Kalibaru Banyuwangi”. Jurnal Manajemen Dan Bisnis Indonesia. Vol 2. No. 1.

Alimuddin, Ibriati Kartika. (2012). "Pengaruh Motivasi Terhadap Produktivitas Kerja Karyawan Pada Pt. Telkom Indonesia, Tbk Cabang Makassar)”. Fakultas Ekonomi Dan Bisnis Universitas Hasanuddin. Makassar.

Atilah. (2014). "Pengaruh Motivasi dan Disiplin Kerja Terhadap Produktivitas Kerja Karyawan Pada Pt Alphacon Valfindo". Fakultas Ekonomi Universitas Serang Raya. Serang.

Krisnayustifa, Khanyy. (2016). "Pengaruh Pemberian Reward dan Punishment terhadap Prestasi Kerja Karyawan di bagian Produksi Surat dan paket barang jenis layanan paket pos biasa pada Kantor pos di Kota Serang”. Fakultas Ekonomi Universitas Serang Raya. Serang.

Zakaria, Nizar. (2016). "Pengaruh Kepuasan Dan Motivasi Kerja Terhadap Produktivitas Kerja Karyawan Pt. Wahana Mitra Karya Persada Cilegon”. Fakultas Ekonomi Universitas Serang Raya. Serang http://administrasibisnis.studentjournal.ub.ac.id/index.php/jab/article/view/236 